\title{
Crush analysis and multi-objective optimization design for circular tube under
} quasi-static lateral loading

\author{
A. Baroutaji ${ }^{1}$, M.D. Gilchrist ${ }^{2}$, D. Smyth ${ }^{3}$, A.G. Olabi $^{3}$ \\ (1)- School of Mechanical and Manufacturing Engineering, Dublin City University, Glasnevin, Dublin 9, Ireland.
}

(2)- School of Mechanical \& Materials Engineering, University College Dublin, Dublin 4, Ireland

(3)- Institute of Engineering and Energy Technologies, School of Engineering, University of the West of Scotland, Paisley,

\begin{abstract}
:
This paper addresses the energy absorption behaviour and crashworthiness optimisation of short length circular tubes under quasi-static lateral loading. Finite element (FE) models were developed using implicit FE code ANSYS to simulate the deformation behaviour and energy absorption of circular tube under lateral loading. These FE models were validated using experimental techniques to ensure that they can predict the responses of circular tube with sufficient accuracy. Response Surface Methodology (RSM) for design of experiments (DOE) was used in conjunction with finite element modelling to evaluate systematically the effects of geometrical parameters on the energy absorption responses of laterally crushed circular tubes. Statistical software package, Design-Expert, was used to apply the response surface methodology (RSM). The energy absorbing responses (specific energy absorbing capacity (SEA) and collapse load (F)) were modelled as functions of geometrical factors (tube diameter, tube thickness, and tube width). These developed functions allow predictions of the energy absorption response of laterally crushed tubes, based on their geometry parameters. Based on DOE results, parametric studies were conducted to generate design information on using the laterally crushed tubes in energy absorbing systems. Finally, the approach of multi-objective optimization
\end{abstract}


design (MOD) was employed to find the optimal configuration of the proposed energy absorption structures. Design-Expert software, which employs the desirability approach as optimization algorithm, was used for solving the MOD problem.

Keywords: Thin-walled circular tube, Energy absorbing systems, lateral collapse, ANSYS, Quasi-static loading, Design of experiment, multi-objective optimisation design.

\section{Introduction:}

In general, crashworthiness is the ability of a structure to protect itself and its occupants from serious injury or death when it is subjected to an impact load.

In the last few decades, there has been a continuous focus on crashworthiness as a primary requirement in the design of occupant-carrying structures.

Thin walled tubes have been extensively employed in crashworthiness applications, to absorb kinetic energy through plastic deformation and thus enhance the crashworthiness of the structure. The widespread use of thin walled tubes as energy absorbers is due to their good performance under dynamic loading, availability, low manufacturing cost, and efficiency. Many applications employ thin walled tubes to enhance the crashworthiness of structure such as energy absorption devices at the front of cars and trains [1], Aircraft sub floor structures [2], Rollover Protective Structures (ROPS) of heavy vehicles, such as bulldozers and tractors [3].

A significant amount of research has been conducted on the energy dissipated by thin-walled tubes. The main findings were outlined and presented in a review article by Olabi et al. [4] and Alghamdi [5]. General information and discussion about energy absorption structures and materials can be found in book by $\mathrm{Lu}$ and $\mathrm{Yu}[6]$. 
Thin-walled tubes can absorb kinetic energy as a result of many types of deformation, leading to various energy absorption responses. The principle ways of destroying tubes include lateral compression [7-11], lateral indentation [12-13], axial crushing [14-16], tube inversion [17], and tube splitting [18].

The axially loaded tubes have widely used as energy absorbing structures and have received considerable attention by the researchers due to the fact that axial crushing of tubes have comparatively high energy absorbing capacity. This behaviour is due to the fact that under axial loading most of the tube's material deforms plastically and participates in the absorption of energy. However, these structures have certain drawbacks such as the very large fluctuations of the collapse load about a mean load and the unstable deformation mode (global bending mode). The energy absorbing capacity of laterally flattened tubes was found to be greater than that of lateral indentation, but not as much as for axial crushing. The main advantage of the laterally loaded tubes is that bending collapse mode generated from lateral loading results in a smooth force-deflection response. Also, the laterally loaded tubes do not undergo any kind of unstable deformation mode even under the off-axis loading. In spite of these advantages of the laterally loaded structures, these energy absorbers have received relatively limited research attention in the literature.

In the past, the study and analysis of energy absorbing devices was performed by several methods such as experimental, empirical, and analytical techniques. In recent times, traditional techniques have been complemented with the finite element method (FEM), which is very powerful tool particularly for performing parametric studies. In addition to FEM, the factorial method is now employed by the researchers to conduct parametric studies. Factorial analysis is an alternative approach to investigate the responses of energy absorbing systems. It is considered as a very 
powerful tool for evaluating the main and interaction effects of the various parameters on the energy absorption responses. It is also used for conducting parametric studies, particularly if statistical approach such as design of experiments (DOE) is employed. The surrogate model method, such as response surface (RS) model, is considered as a common technique for performing factorial analysis of energy absorbing structures. Employing surrogate model method in the field of energy absorbing systems provides the ability to analysis and to perform multiobjective optimization design (MOD) of the energy absorbing structure. The optimization design can be achieved by using the surrogate models in the optimization algorithm, such as the multi-objective particle swarm optimization (MOPSO) algorithm and desirability approach. Many studies have used RSM with the optimization algorithm to seek an optimal design for the thin-walled tubes under pure axial [19-21], bending [22], and oblique loads [23].

Much of the research on the crashworthiness optimization of energy absorption structures has focused on those axially crushed devices. However, the crashworthiness optimization of circular tubes under lateral loading has received no attention in the literature.

This paper aims at addressing the design and optimization issues for the laterally crushed thin-walled circular tubes as energy absorption devices. An integration of finite element modelling (FEM) with the Response Surface Method (RSM) for design of experiments (DOE) was employed for generating the design guidelines for such circular tube as energy absorbing devices. The FE model was developed using commercial finite element code (ANSYS) and validated using experimental techniques. The specific energy absorption (SEA) and the collapse load (F) of the oblong tube were modelled as functions of geometrical parameters such as thickness 
(t), diameter (D), and width (W). Parametric study was performed to investigate the primary and interaction effects of geometric parameters on the SEA and F. Furthermore, multi-objective optimization design (MOD) of the circular tube system is carried out by adopting a desirability approach to achieve maximum SEA capacity and minimum $\mathrm{F}$.

\section{Material and methods}

\subsection{Material properties}

Mild steel tubes were used for manufacturing the empty and nested samples. The steel was cold finished, manufactured according to the DIN standards, DIN 2393 ST 37.2 and contain around $0.15 \%$ carbon. Tensile tests were carried out in order to determine the mechanical properties of the tubes. The dog bones samples (tensile samples) were prepared by flattening the tube and cut the specimens. Figure 1 displays the procedure of tensile test along with the true stress-strain curve obtained. Upon examination of this figure, it can be seen that the stress-strain curve displays unusual behaviour in which strain softening occurred almost immediately after yielding with no evidence of strain hardening. This phenomenon is due to sample necking which takes place immediately after yielding. This behaviour is termed as tension instability and the cold rolling process might be the reason for this. Table 1 shows the mechanical properties of the mild steel material derived from the true stress-strain curve and used in the FE modelling. The yield stress is validated according to DIN standards, which state that the yield stress of this material is within the range of $450-525 \mathrm{MPa}[10,11]$. 


\subsection{Finite element modelling}

\subsubsection{FE model}

An implicit finite element code, ANSYS [24], was employed for creating the FE models of thin-walled circular tubes under quasi-static lateral loading. Since the loading type was quasi-static where the loading rate was slow and there were no dynamic effects, the implicit code (ANSYS) was considered appropriate choice to model both material and geometric non-linearities of the circular tube under quasistatic lateral loading. Many researchers $[10,11]$ used ANSYS software packages to predict the quasi-static response of the energy absorption systems. A 3D-structural solid element (solid 45) that had eight nodes with large strain, large deflection, and plasticity capabilities was used to model the tubes. The moving mass were modelled as rigid body and constrained to move vertically along the y-axis. The base was also modelled as a rigid body with all rotations and translations being fixed. A bilinear isotropic hardening material model was employed to define the material behaviour of the samples. The Young modulus, Poisson's ratio, and yield stress were determined depending on the results of tensile test as shown in Table 1. A non-zero value of $1500 \mathrm{MPa}$ was employed to represent the hardening modulus of this material. This value was selected due to limitation of ANSYS software in defining the softening stage in the bilinear material model, so the value was selected to be as low as possible. The same value of hardening modulus was used by $[10,11]$ to define the softening stage of the same material. An augmented Lagrangian penalty option with a friction coefficient value of 0.2 was employed for all contact pairs. This contact algorithm employs a non-linear surface to surface formulation to define contact between various interacting surfaces. All models were subjected to symmetry 
boundary conditions in order to reduce simulation solving times. Large strain deformation was included in the finite element model due to the test specimen experiencing significantly high displacement. The loads were defined by applying the predefined displacement on the pilot node, which was also used to gather the reaction force from each node. A mesh convergence study was performed to determine the mesh density. It was found that element size of $2 \mathrm{~mm}$ was able to produce a converged solution within a reasonable time. Figure 3 shows the finite element mesh of the half model of the circular tube.

\subsubsection{Validation of FE model}

The numerical results for the circular tubes were validated against the results of the experiments carried out by using Instron machine. The validation was performed by comparing the load-displacement response, energy-displacement response, crush load, specific energy absorbing capacity, and the collapse modes. A prescribed velocity of $10 \mathrm{~mm} / \mathrm{min}$ was applied to the moving crosshead of the instrument during the experiment to ensure that there were no dynamic effects. Many researchers $[10$, 11] used velocities between 0.5 and $15 \mathrm{~mm} / \mathrm{min}$ in the quasi-static lateral compression tests.

Figure 3 shows the comparison of the experimental and numerical force-deflection and energy-deflection responses for circular tube with an outer diameter of $101.6 \mathrm{~mm}$, a thickness of $3.25 \mathrm{~mm}$, and a width of $40 \mathrm{~mm}$ under quasi-static lateral loading. It can clearly be seen that the FE results were in reasonable agreement with the collapse load, followed by a slight over prediction in final stages of the collapse. This overprediction is due to the material stress-strain curve used in this study exhibiting an unusual 'material' strain softening phenomenon that is characterised by a negative slope. This material behaviour cannot be accounted for in the bilinear material 
prediction model since it requires that the data points generate a slope greater than zero. Therefore, it is possible that the finite element model's ability to capture the 'material' strain softening phenomenon with sufficient accuracy is limited. Table 2 shows the comparison of experimental and predicted values of SEA and F. It can be seen that the percentage errors are within acceptable tolerances. From Table 2 and Figure 3 , it is evident that a good correlation was achieved between the FE and experimental results.

The deformation modes of a circular tube under quasi-static lateral loading predicted by the FE code was in close correlation with that from the experimental testing, as shown in Figure 4. In general, the collapse mode of thin-walled tube under quasistatic lateral loading is plastic bending around plastic hinges.

\section{Response surface models}

In this section, Response surface methodology (RSM) for design of experiments (DOE) was used in parallel with the finite element modelling (FEM) to construct the response surface (RS) models. These models relate the energy absorption responses to the geometrical parameters. The RS models are useful formulation which can provide an initial prediction of the energy absorption responses for the thin walled tubes of given dimensions and also can be used to indicate which parameter has the most influence on the energy absorption responses. Furthermore, the RS models can be used for structural optimization after verifying their accuracy as will be shown in section 5. Figure 5 displays the flow chart which explains the steps for constructing the RS models. 


\subsection{Sampling design points}

An experimental design was created based on a three level Box-Behnken design with full replication. The independent variables used in this design were as follows: tube width (W) ranged between 10 and $60 \mathrm{~mm}$, tube outer diameter (D) between 80 and $130 \mathrm{~mm}$, and tube thickness $(\mathrm{t})$ between 2.5 and $6 \mathrm{~mm}$. Table 3 shows the geometrical variables and experimental design values used. The dimensions were chosen to cover the typical range of tube sizes commonly used in crashworthiness applications. The specific energy absorbed (SEA) and collapse load (F) were selected as the design responses. Detailed FE models were created for the circular tubes representing the sampling design points. Numerical simulations were performed for the different combinations of independent variables determined through design of experiment (DOE). The energy absorption responses (SEA and F) were measured for each combination of geometrical factors. The SEA responses for all models have been calculated up to $70 \%$ of the circular tube diameter. The different combinations of design variables with corresponding design responses are tabulated in Table 4.

\subsection{Development of Response Surface (RS) models}

Statistical software, Design-Expert V8 [25], was used to apply Response Surface Methodology (RSM) on the results of the numerical model described and validated earlier in section 2.2. A step-wise regression method was used to fit the polynomial equation (RS model) to the numerical results and to identify the relevant model terms. This method (step-wise regression method) is recommended due to it eliminates the insignificant model terms automatically from the polynomial equation. The statistical significance of the developed models and each term in the regression 
equation were inspected using statistical measure to achieve the best fit. From analysing the measured responses by the Design-expert software, the summary output of best fit indicates that linear and quadratic models are statistically recommended for the specific energy absorption (SEA) and collapse load (F) respectively. The Analysis of variance (ANOVA) methodology was employed by the software to check the adequacy of the developed models. The ANOVA table summarise the analysis of variance for response, and show the significant model terms and the adequacy measures. The adequacy measures are the probability (Model P-value), coefficient of determination R2, Adjusted R2, Predicted R2, and Adequate precision. Table 5 displays the analysis of variance (ANOVA) results generated by the Reduced Linear Model of the SEA response. The model F value of 36.59 indicated that the model was significant. A p-value of 0.0001 suggested that there was a low chance that the F value could occur due to noise in this model. The predicted R2 of 0.7463 is in reasonable agreement with the adjusted R2 of 0.8165 . It can be seen that the predicted R-squared and the adjusted R-squared are within 0.20 of each other, which harmonizes with what it is reported in [25]. The Adeq Precision value measures the signal to noise ratio and it should be greater than 4 as stated by [25]. In this model, the adequate precision was found to be 45.12 indicating an adequate signal. This means that this model can be used to navigate the design space. The analysis of variance indicated that the following terms are the most significant ones that were associated with the specific energy absorbed:

The first order effect of thickness ( $\mathrm{t}$ ) and diameter (D).

The final mathematical models in terms of actual factors as determined by the design expert software are shown in Table 5. The F values of the design variables shown in 
the ANOVA table (Table 5) can be used to indicate the order of the influence of the factors on the resultant SEA. It can be seen that the thickness ( $t$ ) was the most influential factor with the highest F- value of 61.8.

The resulting ANOVA table (Table 6) for the Quadratic Model of response F was constructed. The model $\mathrm{F}$ value of 7096.57 indicates that this model is significant. The p-value of 0.0001 suggests that there is only $0.01 \%$ chance that the $F$ value could occur due to noise. The "Pred R-Squared" of 0.9982 is in excellent agreement with the "Adj R-Squared" of 0.9997. High $\mathrm{R}^{2}$ values suggest that there is a statistically significance correlation between the factors and the response. The adequate precision ratio was found to be 311.457 , which is significantly higher that the significance threshold level of 4 . This means that the model had very little noise; therefore it can be used to navigate the design space. The ANOVA table shows pvalues less than 0.05 for all model terms. Such low p-values highlight the significance of these factors and their interactions. The most significant terms associated with collapse load $(\mathrm{F})$ were as follow:

1. The first order effect of tube diameter (D), tube thickness (t) and tube width (W).

2. The second order effect of tube thickness ( $\mathrm{t}$ ), tube width (W), and tube diameter (D).

3. The two level of interaction effects between the tube thickness and the tube width $(t-w)$, the diameter and $t(D-t)$, the diameter and width $(D-W)$. Resulting F can be modelled by the final equation produced by the model given in Table 6 .

Order of factor influence on collapse load (F) can be established through comparing the F-values magnitudes (Table 6) as follows: $\mathrm{B}>\mathrm{A}>\mathrm{C}>\mathrm{BC}>\mathrm{C}^{2}>\mathrm{AB}>\mathrm{AC}>\mathrm{A}^{2}>\mathrm{B}^{2}$. 


\subsection{Validation of RS models}

Figure 6 and Figure 7 show the relationship between the actual and predicted values of the specific energy absorbed and the collapse force, respectively. These figures indicate that the developed RS models are adequate, as the residuals in the prediction for each response are small since the residuals tend to be close to the diagonal line.

Furthermore, to verify the adequacy of the RS models, a comparison between the numerical, experimental, and predicted responses has been performed. Using the point prediction option in the DOE software, the specific energy absorbed and the collapse load of the validation experiments were predicted using the previously developed models. Table 7 summarises the experimental condition, actual values, numerical values, predicted values, and the percentage error. It can be seen that all the percentage errors are within acceptable tolerances, thus indicating that the RS models were valid.

\section{Parametric study}

The essential design information for thin-walled tubes used as energy absorbing structures can be obtained through performing parametric study. To this end, the DOE results were employed to study the effects of geometrical parameters on the energy absorption responses of circular tubes.

\subsection{Effect of geometrical factors on SEA response}

The analysis of variance (ANOVA) (section 3.2) indicated that SEA depended mainly on the thickness and the diameter of the tube. The insignificant effect of the width on the SEA has been eliminated by the software package. 
Figure 8 shows the variation of the SEA with diameter and thickness. It is seen that the SEA decreases as the tube diameter increase. In spite of increasing the displacement stroke in the larger tubes, the SEA decreased in these tubes. This behaviour is probably due to the deformation mode of circular tube under lateral loading, which is plastic bending around plastic hinges. Because of the strain localization around the plastic hinges, the larger tubes have a smaller relative volume of material subjected to plastic deformation. In addition, the weight of larger tubes is more than that of smaller tubes. Consequently, the energy absorbed per unit mass (SEA) was less in the larger tubes. A similar effect of the tube diameter on the SEA of circular tubes was noticed by Gupta et al [8].

Regarding the effect of tube thickness on the SEA, It can be seen from Figure 8 that the thickness had a significant effect on the SEA and the latter increased as the thickness increased. This trend is due to thicker tubes having more material available for plastic deformation.

Finally, as it can be seen from

Figure 8, the maximum SEA that could be obtained was with a tube with minimum diameter and maximum thickness.

\subsection{Effect of geometrical factors on $F$ response}

The effect of tube diameter on crush force is shown in Figure 9 and Figure 10. It can be seen that the crush force decreased as the tube diameter increased. Increasing the tube diameter leads to a decrease in the stiffness of the tube structure, so larger tubes have lower reaction forces. This behaviour is due to smaller tubes have shorter moment arm from the point of load application to the horizontal hinge points. 
Therefore a greater magnitude of force was required to initiate the collapse in the smaller tubes. A similar phenomenon was observed by [7, 8]. It is clear from Figure 9 and Figure 10 that the thinner and shorter tubes were less influenced by tube diameter as the crush force remained reasonably constant. From the same figures, it can be seen that the crush force increased with increasing thickness and width. The rate of increase of crush load with thickness and width, decreased with increasing tube diameter.

Figure 11 presents the interaction effects of thickness and width on the crush force. The interaction effect occurs when the response is affected by the settings of two factors. It is obvious that the wall thickness had more influence on the crush force as the width increased. Therefore, the wall thickness was more effective for controlling the crush force of wider tubes. In general, the increase in the collapse load with increasing tube thickness and width is due to the greater amount of material across the section of the tube, which effectively increased the lateral stiffness of the tube and hence it required a greater load to initiate the collapse. Figure 12 shows the variation of $\mathrm{F}$ with thickness and width, indicating that a minimum crush force was obtained in the tubes that had a minimum width and thickness.

\section{$5 \quad$ Multi-objective optimization design (MOD)}

While the effect of various parameters on crashworthiness behaviour has been addressed in the previous section, it is still unknown how to design specific best designs for thin-walled circular tubes under the lateral loading. In general, as part of the analysis of energy absorbing components, the various responses being investigated need to be optimized. The single objective optimization approach which considers only one objective was used in lots of studies [26, 27]. This approach is 
not suitable for most of real-life applications which need to consider several objectives simultaneously [28]. So, it is more meaningful to address the design optimization of the energy absorbing structures within multiobjective optimization framework, which could provide more information on the interaction of the different crashworthiness criteria [29].

\subsection{Description of the optimization problem}

As a general rule for the design of energy absorption structures, the structure should absorb as much energy as possible so the SEA was selected as the first objective and maximized. Meanwhile, the energy absorption structure shouldn't transmit too much force to the other parts of the structure and shouldn't cause high decelerations of the occupants in the structure, particularly at the beginning of the impact event where the velocity is too high. To this end, the collapse load (F) was taken as another objective and was minimized during the optimization study.

Therefore, the MOD problem of circular tube under lateral loading can be formulated as follow:

$$
\left\{\begin{array}{c}
\text { Maxmize } f 1=S E A(x) \\
\text { Minmize } \quad f 2=F(x) \\
\text { s.t } \quad x^{l} \leq x \leq x^{u}
\end{array}\right.
$$

Where $\mathrm{x}=\left(\mathrm{x}_{1}, \mathrm{x}_{2} \cdots \mathrm{x}_{\mathrm{k}}\right)$ are the vector of $\mathrm{k}$ design variables of the cross-sectional geometry, $\mathrm{x}^{\mathrm{L}}=\left(\mathrm{x}^{\mathrm{L}}{ }_{1}, \mathrm{x}^{\mathrm{L}}{ }_{2}, \cdots, \mathrm{x}_{\mathrm{k}}^{\mathrm{L}}\right)$ and $\mathrm{x}^{\mathrm{U}}=\left(\mathrm{x}^{\mathrm{U}}{ }_{1}, \mathrm{x}^{\mathrm{U}}{ }_{2}, \cdots, \mathrm{x}_{\mathrm{k}}\right)$ are respectively the lower and upper bounds of the design variables.

Since the crash simulation requires high computational cost, the FE modelling cannot be used directly to solve the MOD problem which requires hundreds of 
performance evaluations. The surrogate models such as RS models are widely used in lieu of nonlinear FEA to solve the MOD problem for fast iteration.

\subsection{Desirability approach:}

Typically, multi-objective optimization problem as formulated in equation 1 can be solved by two methods. One is to investigate all the objectives independently and seeks for a set of optimal solutions (Generally known as the Pareto optimal solution). As an alternative, the second method incorporates the different objective functions into a single cost objective function in terms of a relative performance measure, for example, by using desirability approach (Geometrical average method), and results in a single solution for the optimization problem [20,30,32, and 33]. The second method (desirability approach) was employed in this study due to its simplicity, availability in the design-expert software, relatively low computational cost and fast convergence, and because it offers flexibility in weighting and can assign different importance values for individual responses.

Solving multi-objective optimization problems using the desirability approach consists of a technique that combines multiple responses into a dimension-less measure of performance, called an overall desirability function. In particular, the desirability approach indicates the transforming of each estimated response, Yi, into a unit-less utility bounded by $(0<\mathrm{di}<1)$ called individual desirability, where a greater di value indicates that response value $\mathrm{Yi}$ is more desirable, i.e.: if $\mathrm{di}=0$ this means that the response is completely undesired, while di $=1$ indicates a fully desired response [31].

The shape of the desirability function can be changed for each goal by the weight field "wti". Weights are used to give added emphasis to the upper/lower bounds or to 
emphasize the target value. Weights could be ranged between 0.1 and 10 ; a weight greater than one gives more emphasis to the goal, while a weight less than one gives less emphasis to the goal. With a weight value of one, the values of di will vary between zero and one in a linear mode.

The individual desirability function (di) for an objective function to be maximized can be written in a general form as:

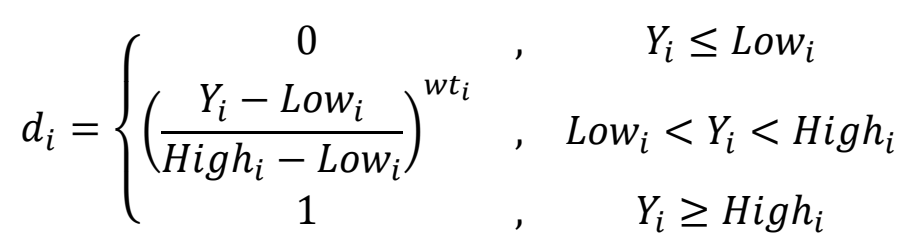

For a minimum value as the required goal, the individual desirability can be defined by

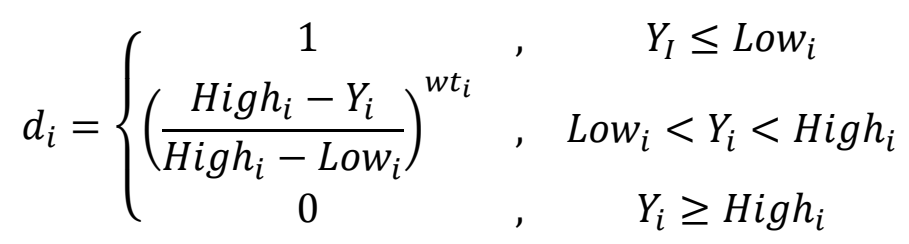

Where $\mathrm{Low}_{\mathrm{i}}$ represents the lower tolerance limit of the response, the High $\mathrm{i}_{\mathrm{i}}$ represents the upper tolerance limit of the response and the super index $\mathrm{wt}_{\mathrm{i}}$ represents the weight factor.

Once these individual di values are determined, they are combined into an overall desirability function D which is calculated as the geometric mean of the di values. In the overall desirability objective function (D), each response can be assigned an importance (r) relative to the other responses. Importance varies from the least important value of $1(+)$, to the most important value of $5(+++++)$.

$$
\mathrm{D}=\left(\prod_{i=1}^{n} d_{i}^{r_{i}}\right)^{\frac{1}{n}}
$$


Where $\mathrm{n}$ denotes the number of responses.

In fact, the desirability approach changes multi-objective problem to a single objective problem by formulating a special objective function called as overall desirability function (D).

\subsection{Design optimization Results:}

In this paper, A multi-objective design was drawn up based on the RS models constructed in section Error! Reference source not found.. The multi-objectives design is aimed at achieving the maximum SEA and to minimize the value of the collapse load (F).

Using the desirability approach, The MOD problem of the laterally crushed thinwalled tubes can be formulated as

$$
\left\{\begin{array}{cc}
\text { Maxmiaze } & \mathrm{D}=\sqrt{\mathrm{d}_{\mathrm{SEA}} \times \mathrm{d}_{\mathrm{F}}} \\
\text { s.t. } & 80 \mathrm{~mm} \leq \mathrm{D} \leq 130 \mathrm{~mm} \\
& 10 \mathrm{~mm} \leq \mathrm{W} \leq 60 \mathrm{~mm} \\
& 2.5 \mathrm{~mm} \leq \mathrm{t} \leq 6 \mathrm{~mm}
\end{array}\right.
$$

Where

$$
\begin{gathered}
d_{S E A}=\left(\frac{S E A(D, W, t)-S E A^{L}}{S E A^{U}-S E A^{L}}\right)^{W_{1}} \\
d_{F}=\left(1-\frac{F(D, W, t)-F^{L}}{F^{U}-F^{L}}\right)^{W_{2}}
\end{gathered}
$$

Where 
$\mathrm{SEA}^{\mathrm{U}}, \mathrm{SEA}^{\mathrm{L}}$ and $\mathrm{F}^{\mathrm{U}}, \mathrm{F}^{\mathrm{L}}$ represent the upper and lower bounds on SEA and $\mathrm{F}$ respectively.

W1, W2 are the weight factors for SEA and F respectively.

Design-Expert software, which employs the desirability approach as an optimization algorithm, was used for solving the MOD problems.

The values of diameter $\mathrm{D}$, thickness $\mathrm{t}$, and width $\mathrm{W}$ were set to vary in order to seek the optimal configuration of the tube. Equal importance was assigned for both objectives but a more emphasis was given to the SEA objective by specifying the maximum weight for it.

The numerical optimization feature in the Design expert V8 software package searches for one or more points in the factors domain that will maximize the desirability function.

The desirability objective function (D) vs design variables $\mathrm{D}$ and $\mathrm{t}$ is shown in Figure 13. It can be seen that the overall desirability increases as the tube thickness increases and the tube diameter decreases.

Table 8 shows the geometrical values which led to a maximum specific energy absorbing capacity while minimizing the crush force. It can be seen that the greatest desirability was offered by the tube with $\mathrm{D}=80 \mathrm{~mm}, \mathrm{t}=6 \mathrm{~mm}$, and $\mathrm{W}=10 \mathrm{~mm}$. Therefore, a multi-objective optimization tube design can be obtained if the tube has a minimum width, a minimum diameter, and a maximum thickness. In general, smaller, shorter, and thicker circular tubes are preferred for use as energy absorbing components.

A numerical FE simulation was carried out to validate the optimized results obtained by the DOE. The comparisons between the predicted and the numerical results are presented in Table 9. It can be seen that the percentage error is within the acceptable 
range, therefore the optimized results are valid. The responses and with the various stages of deformation of the optimal configuration are displayed in Figure 14.

\section{Conclusion}

The Response Surface Method (RSM) for design of experiments (DOE) was used along with the finite element modelling (FEM) to explore the effects of the geometrical factors such as thickness (t), diameter (D), and width (W) on the energy absorption responses of laterally crushed circular tube. The specific energy absorption (SEA) and the collapse load (F) of the circular tube were modelled as functions of geometrical parameters. Based on the developed models of the SEA and F, the approach of multi-objective optimization design was applied to find the optimal configuration of the circular tube. As a practical implication, the main outcomes from the parametric and optimization studies for design purposes are drawn as follows.

- The SEA of circular tubes under lateral loading increased with increasing thickness and decreasing diameter. The effect of tube width on SEA was found to be insignificant.

- The crush force was found to be greater in the smaller tubes. Thinner and shorter circular tubes were less influenced by changing the tube diameter compared to longer and thicker tubes.

- The tubes with smaller width (W) and diameter (D), and higher thickness are more suitable for use as energy absorbing components. The optimum configuration of the tubes was found to be those that have a minimum width and diameter, and maximum thickness. 


\section{Acknowledgment}

The first author wishes to gratefully acknowledge the financial support from the University of Aleppo.

\section{References}

[1] Marsolek, J.and Reimerdes, H., (2004), "Energy absorption of metallic cylindrical shells with induced non-axisymmetric folding patterns", Int.J.Impact Eng., Vol.30 (8), pp. 1209-1223.

[2] Bisagni, C. (2002), "Crashworthiness of helicopter subfloor structures", Int.J.Impact Eng., Vol.27 (10), pp. 1067-1082.

[3] Ahmad, Z.and Thambiratnam, D., (2009), "Application of foam-filled conical tubes in enhancing the crashworthiness performance of vehicle protective structures", International Journal of Crashworthiness, Vol.14 (4), pp. 349-363.

[4] Olabi, A., Morris, E.and Hashmi, M., (2007), "Metallic tube type energy absorbers: A synopsis", Thin-Walled Structures, Vol.45 (7-8), pp. 706-726.

[5] Alghamdi, A.A.A. (2001), "Collapsible impact energy absorbers: an overview", Thin-Walled Structures, Vol.39 (2), pp. 189-213.

[6] Lu, G. and Yu, T., (2003), Energy absorption of structures and materials, , Woodhead Publishing,

[7] DeRuntz Jr, J.A.and Hodge Jr, P., (1963), "Crushing of a tube between rigid plates", Journal of Applied Mechanics, Vol.30 pp. 391. 
[8] Gupta, N., Sekhon, G.and Gupta, P., (2005), "Study of lateral compression of round metallic tubes", Thin-walled structures, Vol.43 (6), pp. 895-922.

[9] Baroutaji, A. and Olabi, A.G., (2012) "Analysis of the Effect of the Elliptical Ratio in Tubular Energy Absorbers Under Quasi-Static Conditions." In Materials with Complex Behaviour II, pp. 323-336. Springer Berlin Heidelberg.

[10] Morris, E., Olabi, A.and Hashmi, M., (2007), "Lateral crushing of circular and non-circular tube systems under quasi-static conditions", Journal of Materials Processing Tech., Vol.191 (1-3), pp. 132-135.

[11] Morris, E., Olabi, A.and Hashmi, M., (2006), "Analysis of nested tube type energy absorbers with different indenters and exterior constraints", Thin-Walled Structures, Vol.44 (8), pp. 872-885.

[12] Sowerby, R., Johnson, W.and Samanta, S., (1968), "The diametral compression of circular rings by point loads", Int.J.Mech.Sci., Vol.10 (5), pp. 369-370.

[13] Jing, Y.Y.and Barton, D.C., (1998), "The response of square cross-section tubes under lateral impact loading", International Journal of Crashworthiness, Vol.3 (4), pp. 359-378.

[14] Rossi, A., Fawaz, Z.and Behdinan, K., (2005), "Numerical simulation of the axial collapse of thin-walled polygonal section tubes", Thin-walled structures, Vol.43 (10), pp. 1646-1661.

[15] Nagel, G.and Thambiratnam, D., (2005), "Computer simulation and energy absorption of tapered thin-walled rectangular tubes", Thin-walled structures, Vol.43 (8), pp. 1225-1242. 
[16] Zhang, X.and Zhang, H., (2013), "Energy absorption of multi-cell stub columns under axial compression", Thin-Walled Structures, Vol.68 pp. 156-163.

[17] Huang, X., Lu, G.and Yu, T.X., (2002), "Energy absorption in splitting square metal tubes", Thin-walled structures, Vol.40 (2), pp. 153-165.

[18] Zarei, H.and Kröger, M., (2008), "Optimization of the foam-filled aluminum tubes for crush box application", Thin-Walled Structures, Vol.46 (2), pp. 214-221.

[19] Hou, S., et al., (2007), "Design optimization of regular hexagonal thin-walled columns with crashworthiness criteria", Finite Elements Anal.Des., Vol.43 (6), pp. $555-565$.

[20] Hou, S., et al., (2008), "Multiobjective optimization of multi-cell sections for the crashworthiness design", Int.J.Impact Eng., Vol.35 (11), pp. 1355-1367.

[21] Liu, Y. (2008), "Crashworthiness design of multi-corner thin-walled columns", Thin-Walled Structures, Vol.46 (12), pp. 1329-1337.

[22] Liu, Y. (2008), "Optimum design of straight thin-walled box section beams for crashworthiness analysis", Finite Elements Anal.Des., Vol.44 (3), pp. 139-147.

[23] Qi, C., Yang, S.and Dong, F., (2012), "Crushing analysis and multiobjective crashworthiness optimization of tapered square tubes under oblique impact loading", Thin-Walled Structures, Vol.59 pp. 103-119.

[24] ANSYS® Academic Research, Release 14.0, Help System, ANSYS LS-DYNA User's Guide, ANSYS, Inc. 2009. 
[25] Stat-Ease Inc. 'Design-Expert software V8 user's guide',Technical Manual, Stat Ease, Inc., Minneapolis, MN,2010.

[26] Hanssen AG, Hopperstad OS, Langseth M. Design of aluminium foam-filled crash boxes of square and circular cross-sections. Int J Crashworth 2001;6(2):17788.

[27] Hanssen AG, Langseth M, Hopperstad OS. Optimum design for energy absorption of square aluminium columns with aluminium foam filler. Int J Mech Sci 2001;43(1):153-76.

[28] Zarei, H. R., and M. Kröger. "Multiobjective crashworthiness optimization of circular aluminum tubes." Thin-walled structures 44.3 (2006): 301-308.

[29] Nariman-Zadeh, N., A. Darvizeh, and A. Jamali. "Pareto optimization of energy absorption of square aluminium columns using multi-objective genetic algorithms." Proceedings of the Institution of Mechanical Engineers, Part B: Journal of Engineering Manufacture 220.2 (2006): 213-224.

[30] Baroutaji, A., E. Morris, and A. G. Olabi. "Quasi-static response and multiobjective crashworthiness optimization of oblong tube under lateral loading."ThinWalled Structures 82 (2014): 262-277.

[31] Myers, R.H. and Anderson-Cook, C.M., (2009), Response surface methodology: process and product optimization using designed experiments, , John Wiley \& Sons,.

[32] Hou, S., et al., (2009), "Crashworthiness design for foam filled thin-wall structures", Mater Des, Vol.30 (6), pp. 2024-2032. 
[33] Salehghaffari, Shahabedin, Masoud Rais-Rohani, and Ali Najafi. "Analysis and optimization of externally stiffened crush tubes." Thin-walled structures 49.3 (2011): 397-408. 
Figure 1: (a) - The tensile test procedure, (b) - True stress-strain curves obtained from tensile tests.

Figure 2: FE model of circular tube under quasi-static lateral loading.

Figure 3: Comparison of FE \& experimental results for a circular tube.

Figure 4: Comparison of (a) the experimental and (b) the numerical deformation mode of circular tube under quasi-static lateral loading.

Figure 5: Flow chart showing the steps of creating the RS models

Figure 6: Scatter diagram of SEA.

Figure 7: Scatter diagram of F.

Figure 8: Variation of SEA with D \& $\mathrm{t}$.

Figure 9: Interaction effects of $\mathrm{D}$ and $\mathrm{t}$ on $\mathrm{F}$.

Figure 10: Interaction effect $\mathrm{D}$ and $\mathrm{W}$ on $\mathrm{F}$.

Figure 11: Interaction effect of $\mathrm{t}$ and $\mathrm{W}$ on $\mathrm{F}$.

Figure 12: Variation of $\mathrm{F}$ with $\mathrm{W}$ and $\mathrm{t}$.

Figure 13: Surface of desirability objective function (D) vs. design variables.

Figure 14: Responses and deformation history of the optimal configuration. 
Table 1: Material properties of empty and nested tubes

Table 2: Comparison of the FEA results with the Experimental results for a circular tube

Table 3: Independent variables and experimental design levels that were used.

Table 4: The design matrix.

Table 5: Analysis of variance (ANOVA) table for SEA - Reduced Linear Model

Table 6: Analysis of variance (ANOVA) table for F-Quadratic model

Table 7: Confirmation experiment.

Table 8: Optimal solution as obtained by Design-Expert.

Table 9: Confirmation experiment of optimal solution. 
Figure 1: (a) - The tensile test procedure, (b) - True stress-strain curves obtained from tensile tests.

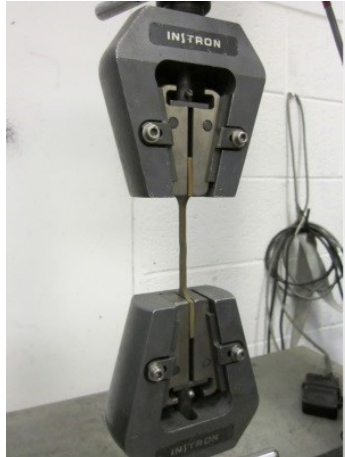

$\boldsymbol{a}$

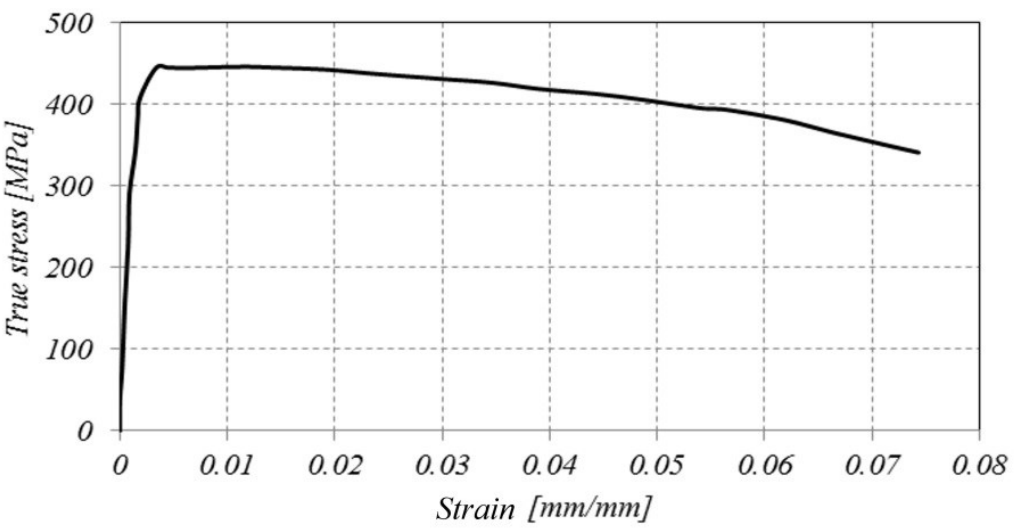

$b$ 
Figure 2: FE model of circular tube under quasi-static lateral loading.

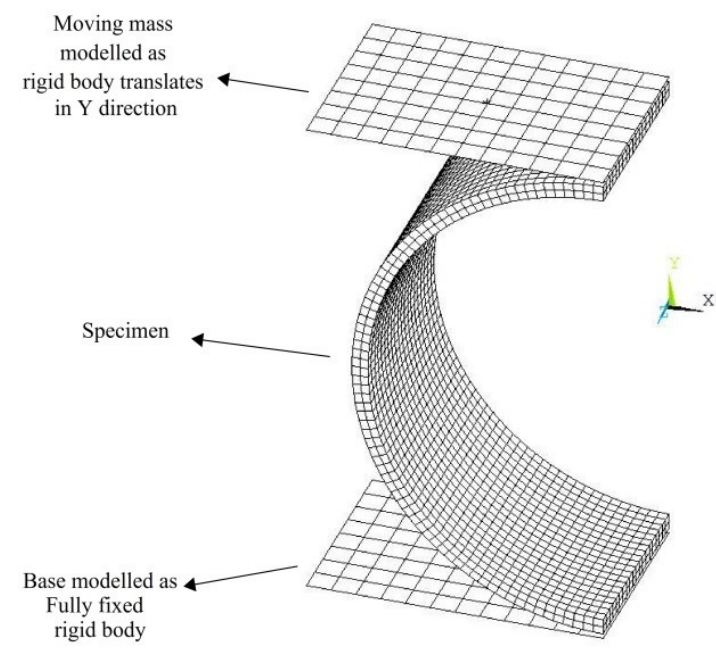


Figure 3: Comparison of FE \& experimental results for a circular tube.

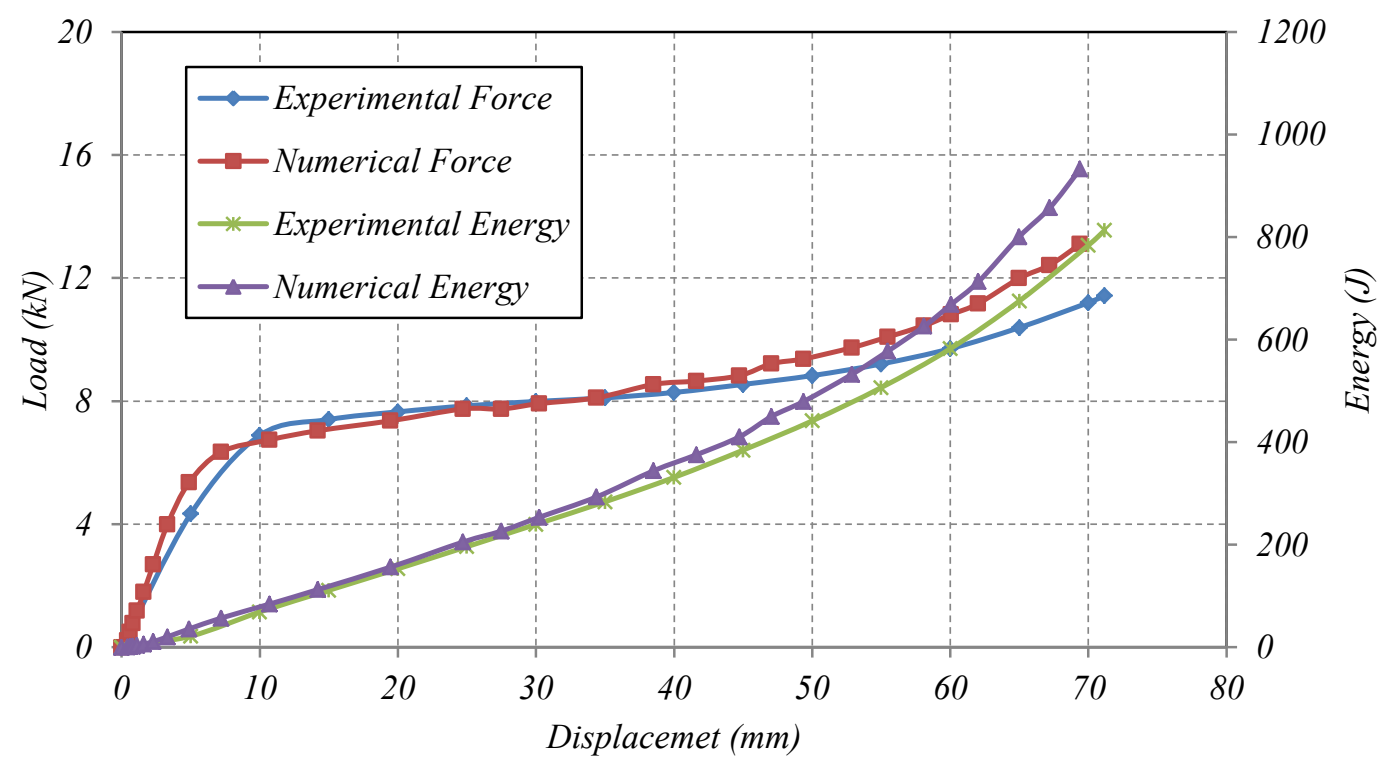


Figure 4: Comparison of (a) the experimental and (b) the numerical deformation mode of circular tube under quasi-static lateral loading.
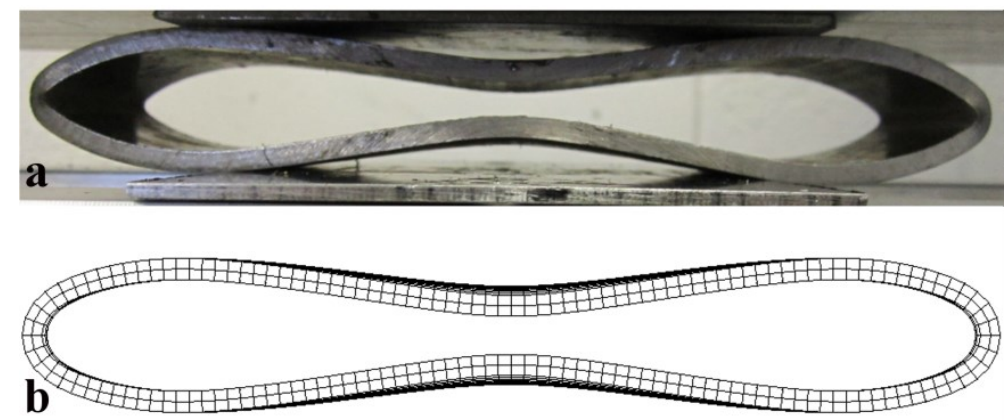
Figure 5: Flow chart showing the steps of creating the RS models

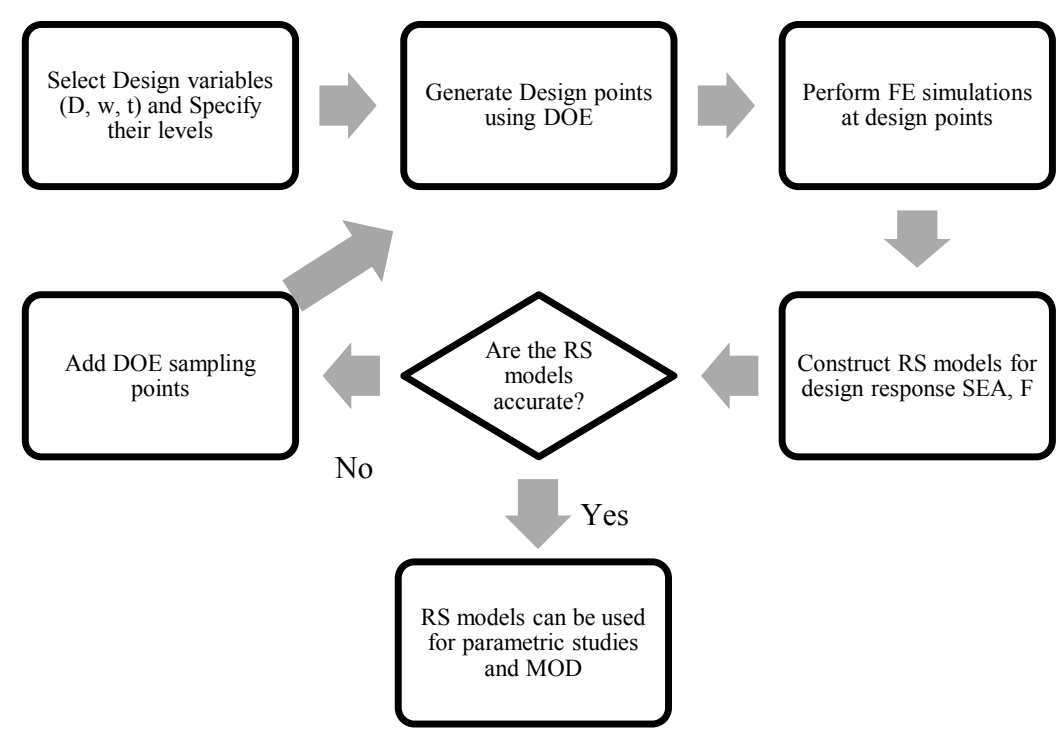


Figure 6: Scatter diagram of SEA.

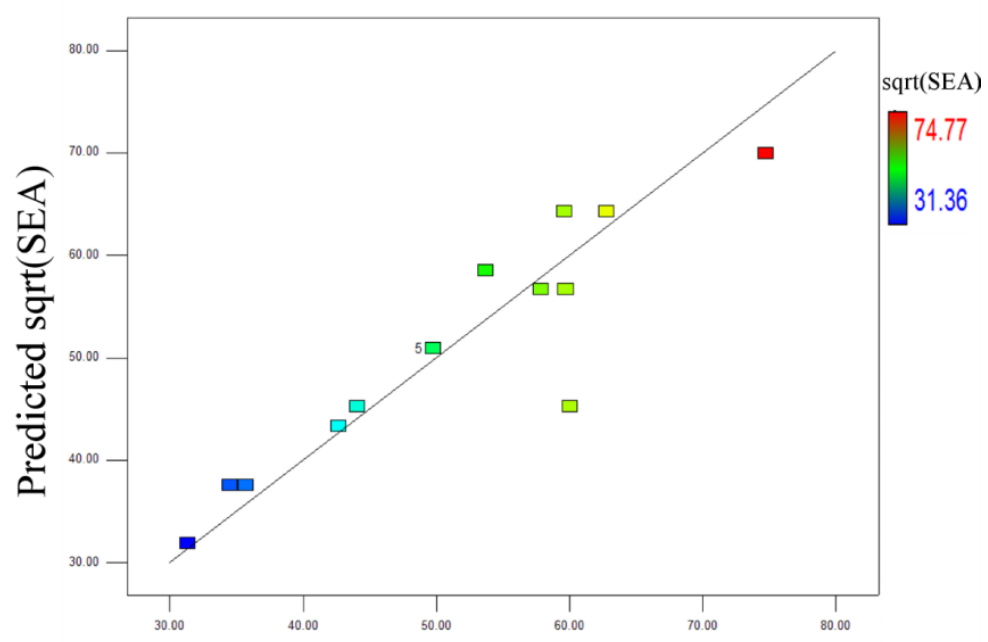

Actual sqrt(SEA) 
Figure 7: Scatter diagram of F.

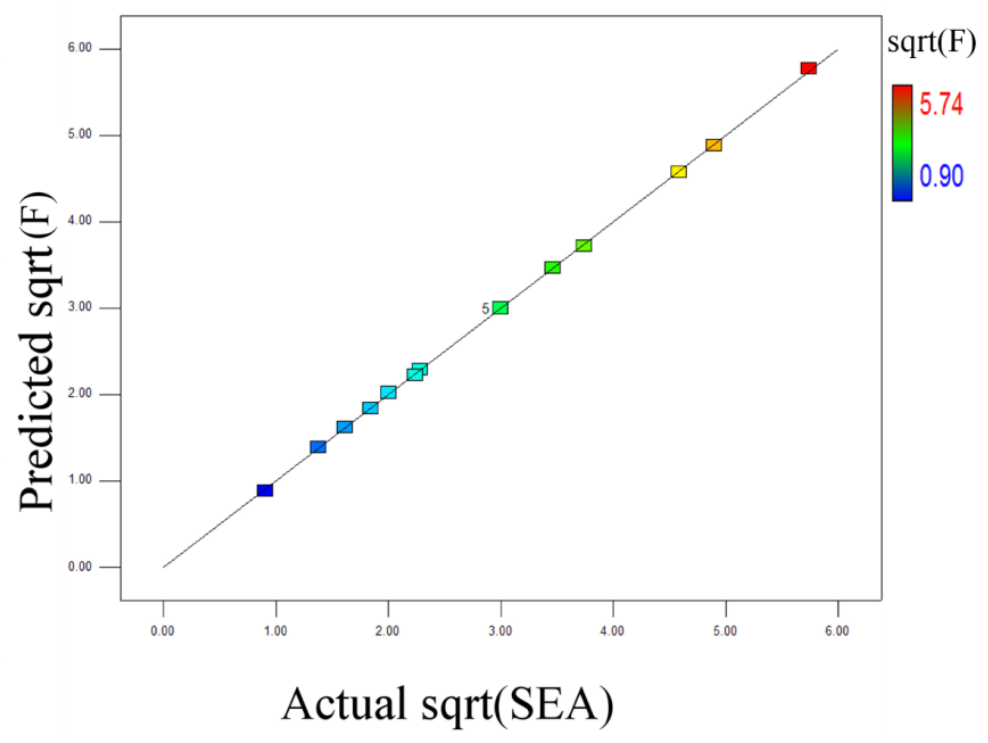


Figure 8: Variation of SEA with D \& $\mathrm{t}$.

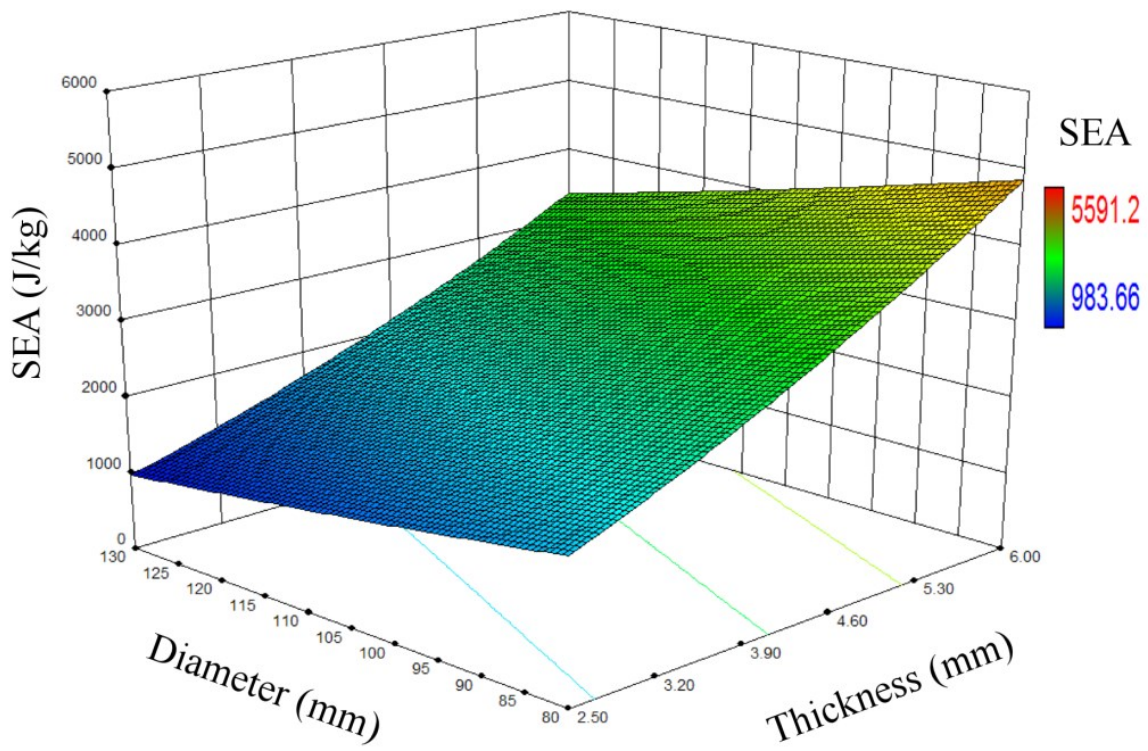


Figure 9: Interaction effects of $\mathrm{D}$ and $\mathrm{t}$ on $\mathrm{F}$.

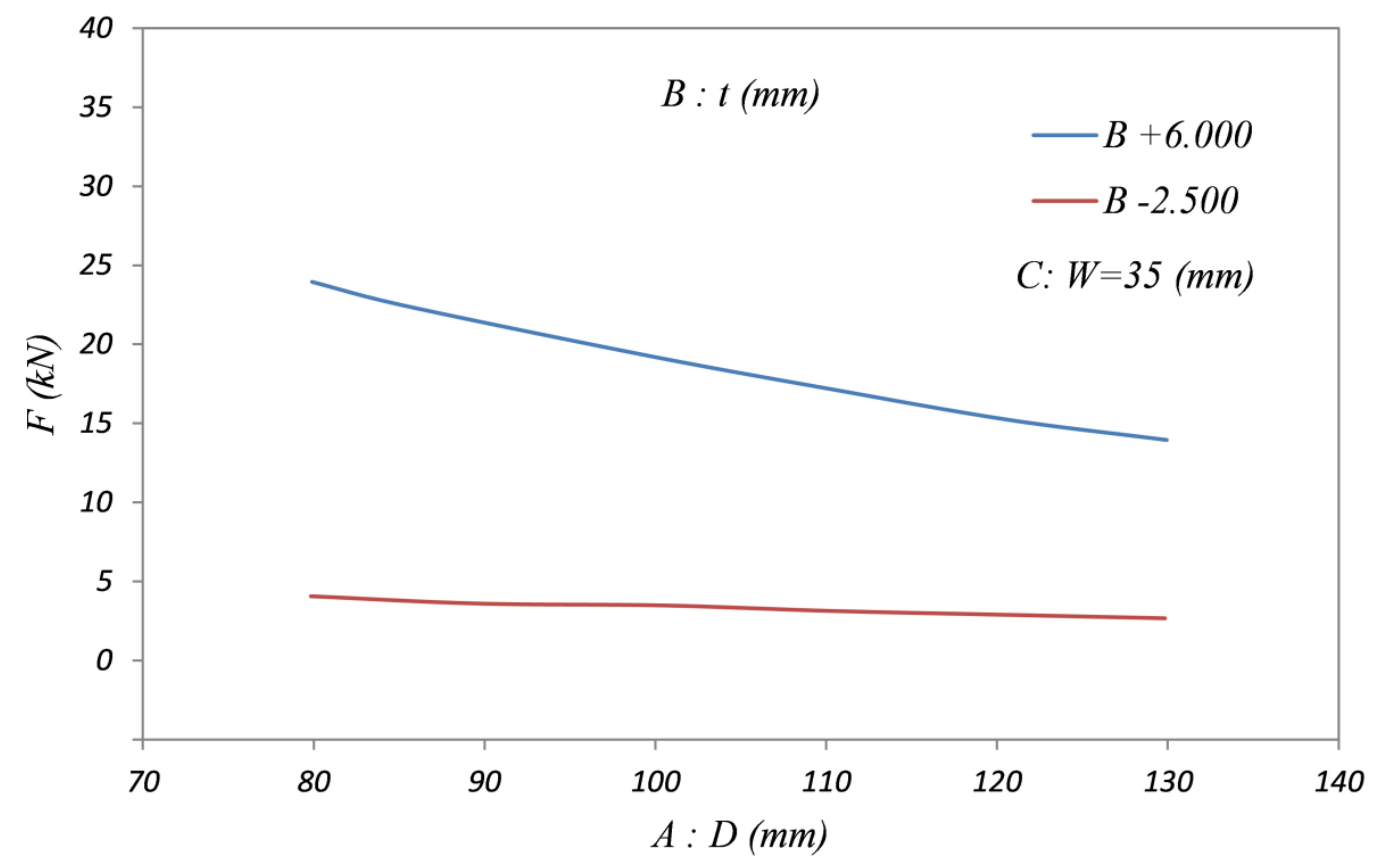


Figure 10: Interaction effect $\mathrm{D}$ and $\mathrm{W}$ on $\mathrm{F}$.

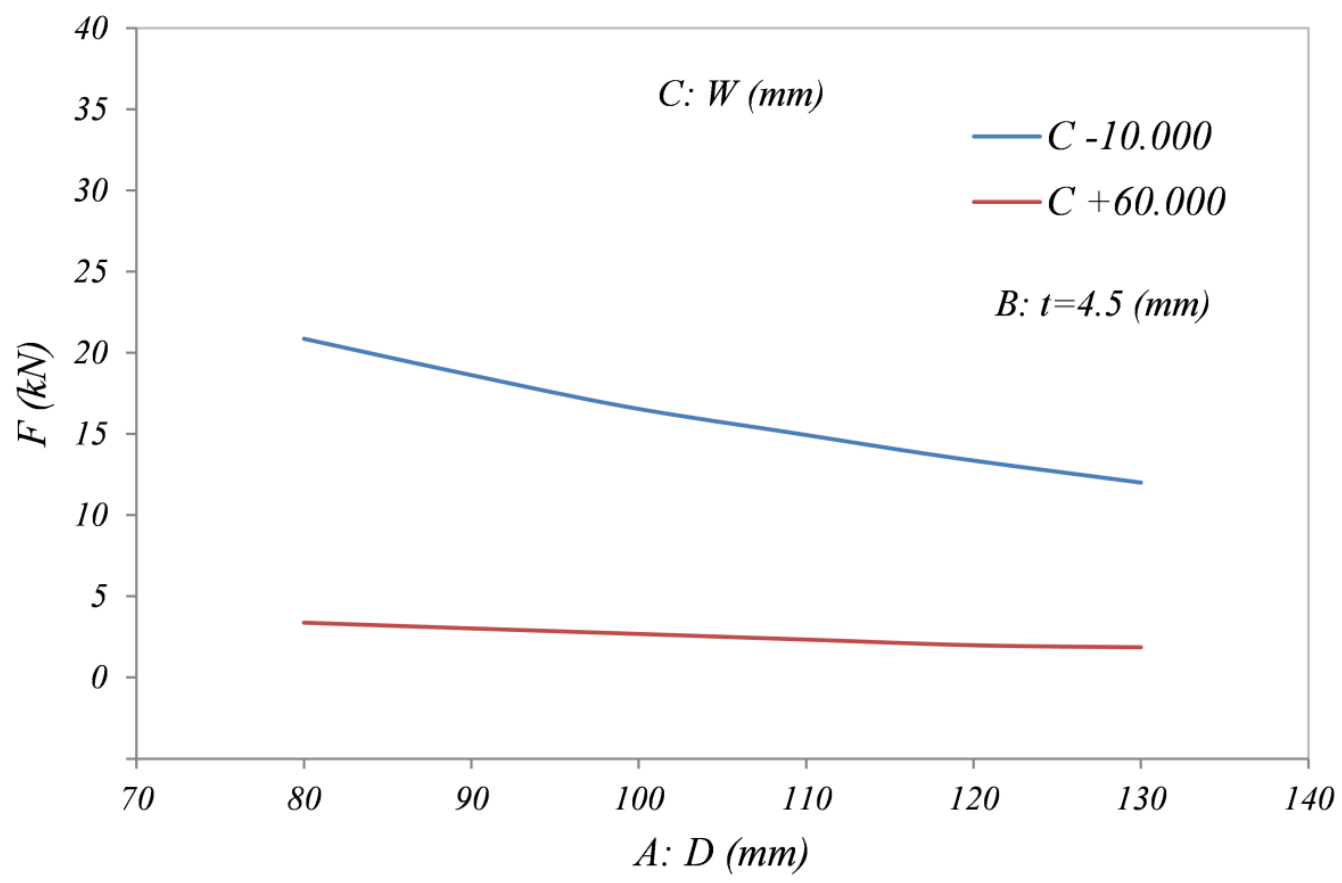


Figure 11: Interaction effect of $\mathrm{t}$ and $\mathrm{W}$ on $\mathrm{F}$.

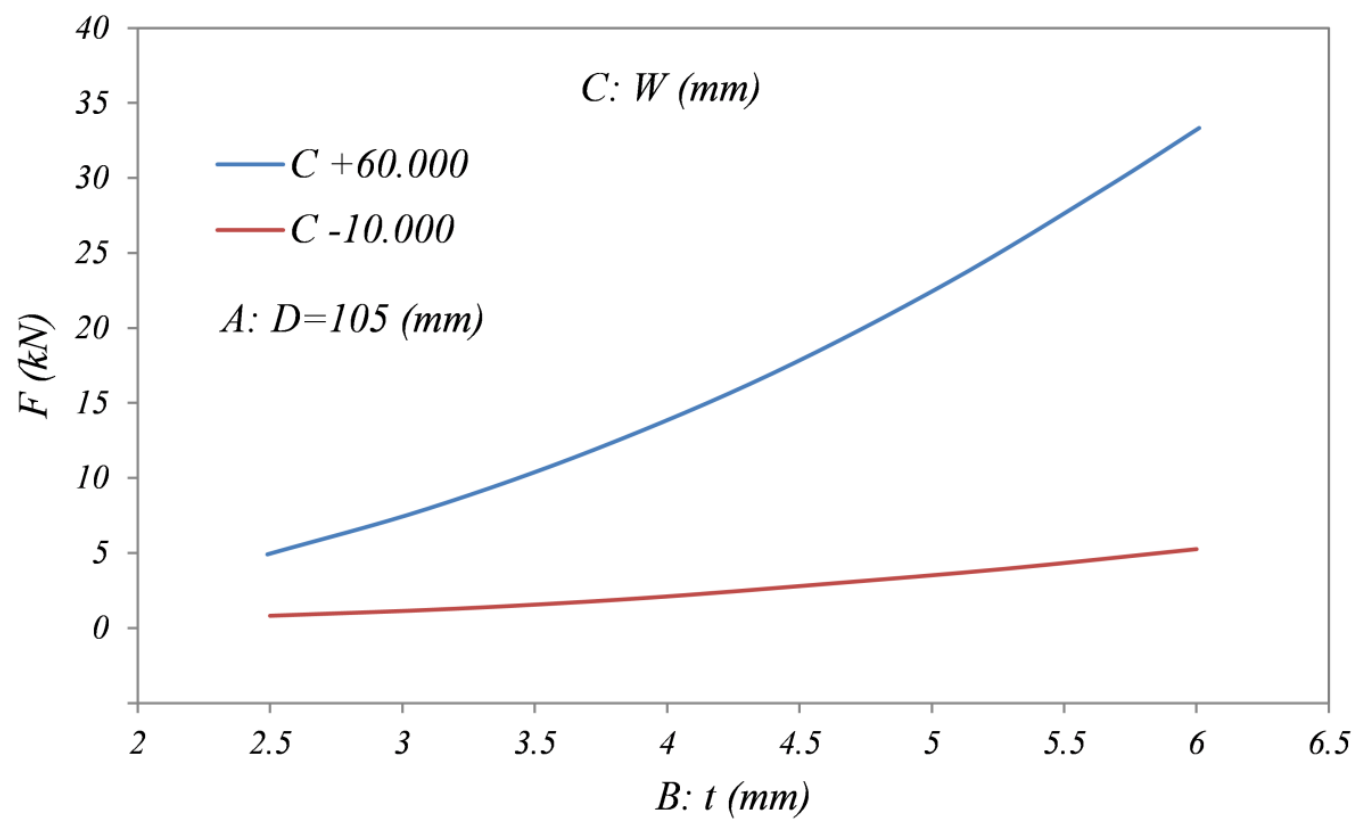


Figure 12: Variation of $\mathrm{F}$ with $\mathrm{W}$ and $\mathrm{t}$.

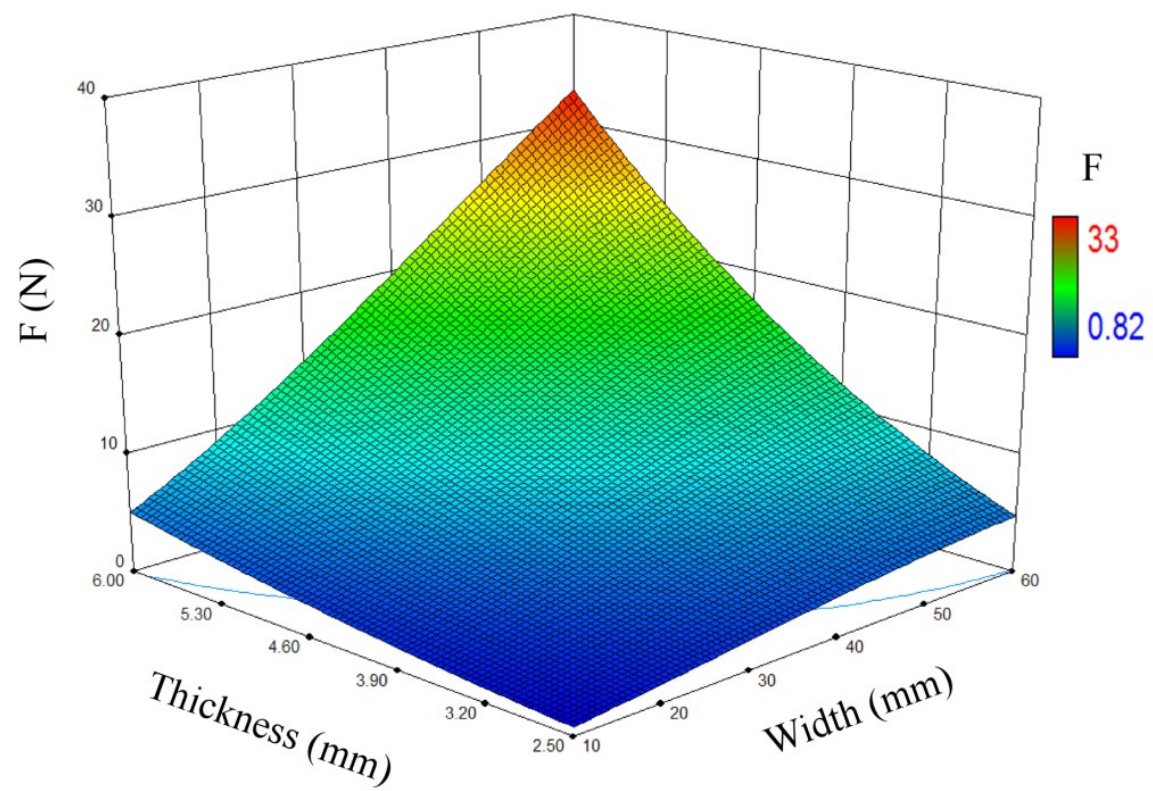

$\mathrm{D}=105(\mathrm{~mm})$ 
Figure 13: Surface of desirability objective function (D) vs. design variables.

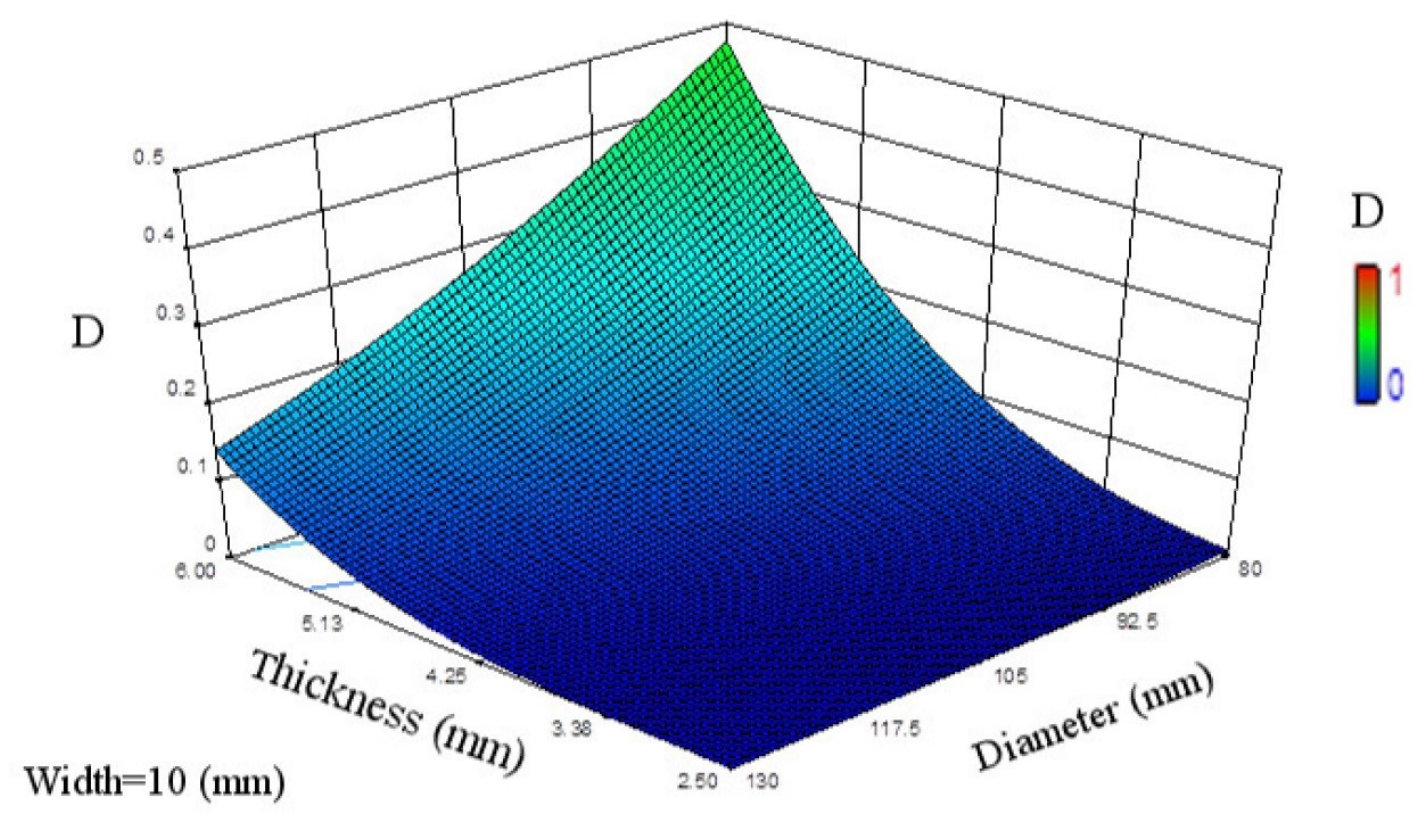


Figure 14: Responses and deformation history of the optimal configuration.
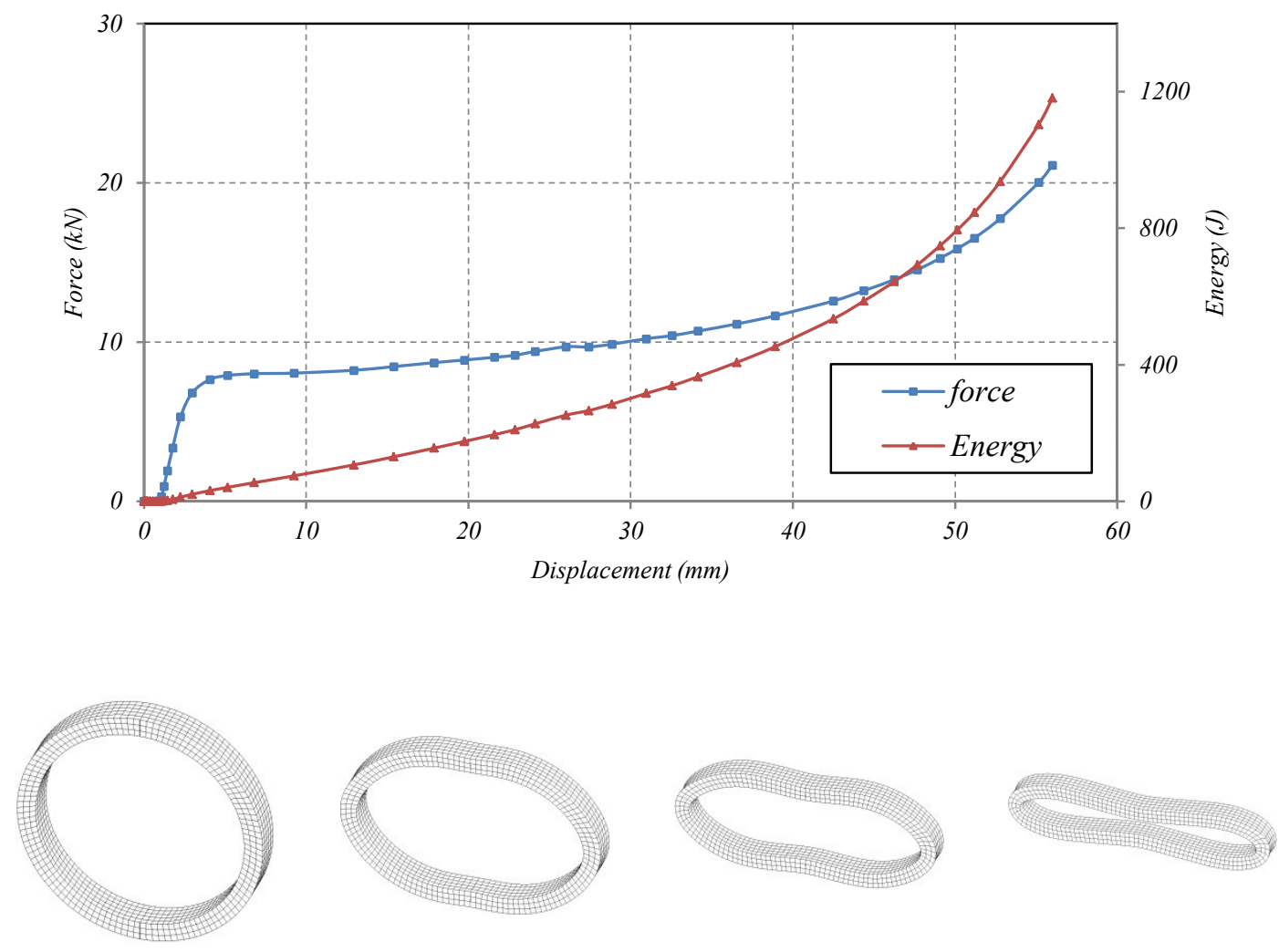

$0(\mathrm{~mm})$

$20(\mathrm{~mm})$

$40(\mathrm{~mm})$

$56(\mathrm{~mm})$ 
Table 1: Material properties of empty and nested tubes

\begin{tabular}{|c|c|c|c|c|}
\hline & Density & Young's & Poisson's & Yield strength \\
& $(\mathrm{kg} / \mathrm{m} 3)$ & modulus $(\mathrm{GPa})$ & ratio & $R p 0.2(\mathrm{MPa})$ \\
\hline DIN 2393-ST 37.2 & 7861 & 200 & 0.3 & 470 \\
\hline
\end{tabular}


Table 2: Comparison of the FEA results with the Experimental results for a circular tube

\begin{tabular}{|c|c|c|}
\hline & SEA[J/kg] & F crush $[\mathrm{kN}]$ \\
\hline Experimental & 1761.15 & 6.8 \\
\hline Numerical & 1791 & 6.3 \\
\hline Error & $1.7 \%$ & $7 \%$ \\
\hline
\end{tabular}


Table 3: Independent variables and experimental design levels that were used.

\begin{tabular}{|c|c|c|c|c|}
\hline \multicolumn{1}{|c|}{ Geometry } \\
\hline Variable & code & -1 & 0 & 1 \\
\hline Diameter(mm) & $\mathrm{A}$ & 80 & 105 & 130 \\
\hline Width(mm) & $\mathrm{B}$ & 10 & 35 & 60 \\
\hline Thickness(mm) & $\mathrm{C}$ & 2.5 & 4.25 & 6 \\
\hline
\end{tabular}


Table 4: The design matrix.

\begin{tabular}{|c|c|c|c|c|c|}
\hline Exp no & $D(m m)$ & $W(\mathrm{~mm})$ & $t(\mathrm{~mm})$ & $S E A(J / k g)$ & $F(k N)$ \\
\hline 1 & 105 & 4.25 & 35 & 2479.676 & 9 \\
\hline 2 & 105 & 4.25 & 35 & 2479.676 & 9 \\
\hline 3 & 130 & 2.5 & 35 & 983.6662 & 2.6 \\
\hline 4 & 105 & 4.25 & 35 & 2479.676 & 9 \\
\hline 5 & 105 & 4.25 & 35 & 2479.676 & 9 \\
\hline 6 & 105 & 2.5 & 10 & 1192.236 & 0.82 \\
\hline 7 & 80 & 4.25 & 60 & 3567.553 & 21 \\
\hline 8 & 130 & 4.25 & 10 & 3606.76 & 1.9 \\
\hline 9 & 105 & 6 & 60 & 3944.481 & 33 \\
\hline 10 & 130 & 6 & 35 & 2885.621 & 14 \\
\hline 11 & 105 & 6 & 10 & 3558.28 & 5.2 \\
\hline 12 & 80 & 2.5 & 35 & 1819.339 & 4 \\
\hline 13 & 80 & 4.25 & 10 & 3345.156 & 3.4 \\
\hline 14 & 130 & 4.25 & 60 & 1945.13 & 12 \\
\hline 15 & 80 & 6 & 35 & 5591.202 & 24 \\
\hline 16 & 105 & 4.25 & 35 & 2479.676 & 9 \\
\hline 17 & 105 & 2.5 & 60 & 1277.148 & 5 \\
\hline
\end{tabular}


Table 5: Analysis of variance (ANOVA) table for SEA - Reduced Linear Model

\begin{tabular}{|c|c|c|c|c|}
\hline Source & Sum of Squares & Mean Square & $F$ Value & p-value \\
\hline Model & 1683.86 & 841.93 & 36.59 & $<0.0001$ \\
\hline A-Diameter & 261.67 & 261.67 & 11.37 & 0.0046 \\
\hline C-Thickness & 1422.19 & 1422.19 & 61.80 & $<0.0001$ \\
\hline Residual & 322.16 & 23.01 & & \\
\hline Cor Total & 2006.02 & & & \\
\hline & & \multicolumn{3}{|c|}{ Final equation obtained from the mode for } \\
\hline$R$-Squared & 0.8394 & \multicolumn{3}{|c|}{ Sqrt(SEA) } \\
\hline $\begin{array}{c}\text { Adj R-Squared } \\
\text { Pred R- }\end{array}$ & 0.8165 & \multicolumn{3}{|c|}{$=+42.57734-0.22877 *$ Diameter } \\
\hline & 0.7463 & \multirow{2}{*}{\multicolumn{3}{|c|}{$+7.61897^{*}$ Thickness }} \\
\hline & 18.909 & & & \\
\hline
\end{tabular}


Table 6: Analysis of variance (ANOVA) table for F-Quadratic model

\begin{tabular}{|c|c|c|c|c|}
\hline Source & Sum of Squares & Mean Square & F-value & p-value \\
\hline Model & 26.68 & 2.96 & 7096.57 & $<0.0001$ \\
\hline A-Diameter & 1.22 & 1.22 & 2928.97 & $<0.0001$ \\
\hline B-Width & 12.28 & 12.28 & 29391.60 & $<0.0001$ \\
\hline C-Thickness & 11.57 & 11.57 & 27683.08 & $<0.0001$ \\
\hline$A B$ & 0.15 & 0.15 & 354.57 & $<0.0001$ \\
\hline$A C$ & 0.11 & 0.11 & 255.13 & $<0.0001$ \\
\hline$B C$ & 1.14 & 1.14 & 2724.17 & 0.0015 \\
\hline$A^{2}$ & 8.317E-003 & 8.317E-003 & 19.91 & 0.0029 \\
\hline$B^{2}$ & $1.492 \mathrm{E}-003$ & $1.492 \mathrm{E}-003$ & 3.57 & 0.1007 \\
\hline$C^{2}$ & 0.22 & 0.22 & 520.21 & $<0.0001$ \\
\hline Residual & $2.925 \mathrm{E}-003$ & $4.178 \mathrm{E}-004$ & & \\
\hline Cor Total & 26.69 & \multirow{2}{*}{\multicolumn{3}{|c|}{ Final equation obtained from the }} \\
\hline & & & & \\
\hline$R$-Squared & 0.9999 & \multirow{4}{*}{\multicolumn{3}{|c|}{ 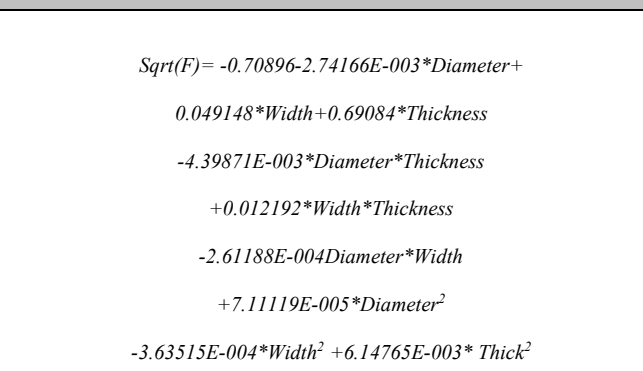 }} \\
\hline Adj R-Squared & 0.9997 & & & \\
\hline Pred R-Squared & 0.9982 & & & \\
\hline Adeq Precision & 311.457 & & & \\
\hline
\end{tabular}


Table 7: Confirmation experiment.

\begin{tabular}{|c|c|c|c|c|c|}
\hline$D(\mathrm{~mm})$ & $t(\mathrm{~mm})$ & $w(\mathrm{~mm})$ & & $\operatorname{SEA}(\mathrm{J} / \mathrm{kg})$ & $F(\mathrm{kN})$ \\
\hline 101.6 & 3.25 & 40 & Experimental & 1761.15 & 6.8 \\
\hline & & & Numerical & 1791 & 6.3 \\
\hline & & & Error (\%) & $1.7 \%$ & $0.60 \%$ \\
\hline & & & Predicted (RSM) & 1944.5 & 6.31 \\
\hline & & & Error (\%) & $8.5 \%$ & $0.15 \%$ \\
\hline
\end{tabular}


Table 8: Optimal solution as obtained by Design-Expert.

\begin{tabular}{|c|c|c|c|c|c|c|}
\hline Number & Diameter & Thickness & Width & SEA & $F(k N)$ & Desirability \\
\hline 1 & 80 & 6.00 & 10.00 & 4899 & 7.6149 & 0.402117 \\
\hline
\end{tabular}


Table 9: Confirmation experiment of optimal solution.

\begin{tabular}{|c|c|c|}
\hline & SEA[J/kg] & $F[\mathrm{kN}]$ \\
\hline Numerical & 5300 & 7.6 \\
\hline Predicted & 4899 & 7.61 \\
\hline Error & $8 \%$ & $0 \%$ \\
\hline
\end{tabular}

